\title{
Autoimmune Hepatitis: Serum Autoantibodies in Clinical Practice
}

\author{
Benedetta Terziroli Beretta-Piccoli ${ }^{1,2,3}$ (1) Giorgina Mieli-Vergani ${ }^{3,4} \cdot$ Diego Vergani $^{3,5}$
}

Accepted: 24 August 2021 / Published online: 7 September 2021

(c) The Author(s) 2021

\begin{abstract}
Circulating autoantibodies are a key diagnostic tool in autoimmune hepatitis (AIH), being positive in $95 \%$ of the cases if tested according to dedicated guidelines issued by the International Autoimmune Hepatitis Group. They also allow the distinction between type $1 \mathrm{AIH}$, characterized by positive anti-nuclear and/or anti-smooth muscle antibody, and type $2 \mathrm{AIH}$, characterized by positive anti-liver kidney microsomal type 1 and/or anti-liver cytosol type 1 antibody. Anti-soluble liver antigen is the only AIH-specific autoantibody, and is found in 20-30\% of both type 1 and type 2 AIH. Anti-neutrophil cytoplasmic antibody is frequently positive in type $1 \mathrm{AIH}$, being associated also with inflammatory bowel disease and with primary/ autoimmune sclerosing cholangitis. The reference method for autoantibody testing remains indirect immunofluorescence on triple tissue (rodent liver, kidney and stomach), allowing both the detection of the majority of liver-relevant reactivities, including those autoantibodies whose molecular target antigens are unknown. Of note, the current knowledge of the clinical significance of autoantibodies relies on studies based on this technique. However, immunofluorescence requires trained laboratory personnel, is observer-dependent, and lacks standardization, leading to ongoing attempts at replacing this method with automated assays, the sensitivity, and specificity of which, however, require further studies before they can be used as a reliable alternative to immunofluorescence; currently, they may be used as complementary to immunofluorescence.
\end{abstract}

Keywords Autoimmune hepatitis $\cdot$ Autoantibodies $\cdot$ Indirect immunofluorescence $\cdot$ Automated assays

\section{Introduction}

Autoimmune hepatitis (AIH) is a chronic inflammatory disorder characterized by loss of tolerance towards hepatic autoantigens, leading to an autoimmune attack to the liver [1]. Clinical features of the disease include female preponderance, elevated serum immunoglobulin $\mathrm{G}(\mathrm{IgG})$ levels, positive circulating autoantibodies, interface hepatitis at liver histology, and a swift response to corticosteroid

Benedetta Terziroli Beretta-Piccoli

benedetta.terziroli@usi.ch; benedetta.terziroli@hin.ch

1 Epatocentro Ticino \& Facoltà Di Scienze Biomediche, Università Della Svizzera Italiana, Lugano, Switzerland

2 Institute for Research in Biomedicine, Bellinzona, Switzerland

3 King's College London Faculty of Life Sciences \&, Medicine At King's College Hospital, London, UK

4 Paediatric Liver, GI and Nutrition Centre, MowatLabs, King's College Hospital, London, UK

5 Institute of Liver Studies, MowatLabs, King's College Hospital, London, UK treatment [2]. AIH affects all ages and races, and is subdivided into type 1 (AIH-1) and type 2 AIH (AIH-2): AIH-1 is by far more common and affects both children and adults, whereas AIH-2 is mainly a paediatric disease [3]. AIH-1 is characterized by positive anti-nuclear antibody (ANA) and/ or anti-smooth muscle antibody (SMA), whereas AIH-2 is characterized by positive anti-liver kidney microsomal antibody type 1 (LMK1) and/or anti-liver cytosol type 1 (LC1) antibody [4, 5]. AIH presentation is variable: it can present acutely with symptoms resembling those of viral hepatitis, e.g. malaise, nausea/vomiting, anorexia, joint and abdominal pain, accompanied by jaundice, dark urine, and pale stools; with fulminant hepatic failure and encephalopathy; insidiously, with non-specific symptoms (progressive fatigue, amenorrhea, headache, anorexia, joint and abdominal pain, diarrhoea, weight loss), lasting from 6 months to a few years before diagnosis; with established chronic liver disease and complications of cirrhosis and portal hypertension (hematemesis from oesophageal/gastric varices, bleeding diathesis, splenomegaly), without a previous history of jaundice or liver disease; and at times is diagnosed after an incidental finding of abnormal transaminase levels, without hepatic 
symptoms or signs. AIH therefore should be excluded in all patients for whom a clear alternative diagnosis is not reached $[1,2]$.

While untreated AIH has a poor prognosis, with a $56 \%$ mortality rate during a follow-up of 30-72 months, up to $90 \%$ of patients respond well to immunosuppressive treatment and have excellent long-term outcomes [6-9]: therefore, timely diagnosis and adequate treatment initiation are key to prevent disease progression. Circulating autoantibodies represent an essential diagnostic tool in clinical practice, being positive in up to 95\% of AIH patients if tested according to dedicated guidelines [10]. Therefore, physician's awareness of the clinical significance of autoimmune liver serology is a prerequisite for properly requesting autoantibody testing and for interpreting laboratory results. On the other hand, the clinical laboratory needs to adhere to established guidelines on autoimmune liver serology testing methods, including reporting all observed specificities to the clinician. This article offers a comprehensive overview on the current methods of detection and on the clinical significance of autoantibodies in $\mathrm{AIH}$, as well as on future perspectives to improve their clinical utility.

\section{Methods of Detection}

The reference method to test liver-related autoantibodies is still indirect immunofluorescence (IIF) on triple rodent tissue, i.e. liver, kidney, and stomach [11], on which the current knowledge of the clinical significance of autoimmune liver serology is based. This technique allows the simultaneous detection of the main liver-related autoantibodies, including ANA, SMA, antiLKM1, anti-LC1, and the anti-mitochondrial antibody (AMA), which is the serological hallmark of primary biliary cholangitis (PBC) [12], but can occasionally be present in AIH [13]. A second major advantage of IIF is its capacity to detect autoantibodies whose target antigens are still unknown. However, it requires trained laboratory personnel, is observer-dependent, and is poorly standardized. Moreover, the quality of the substrates differs among laboratories/manufacturers and over time, the studies investigating clinical associations dating back to the 1970s and 1980s, when fresh rodent tissues were used in contrast to currently fixed and commercially available tissue slide substrates. Comparative studies are lacking. Therefore, attempts to replace IIF on triple rodent tissues with immunochemical techniques or with IIF on HEp-2 cells, a widely used cell line derived from a human laryngeal carcinoma, are ongoing, but need validation [14]. Solid-phase assays have been established and are constantly ameliorated for autoantibodies whose target antigens have been identified, i.e. anti-LKM1, anti-LC1, AMA, and to some extent, ANA and SMA.
According to the recommendations issued in 2004 by the Committee for Autoimmune Serology of the International Autoimmune Hepatitis Group (IAIHG), diluted patient serum is incubated with the tissue substrates, allowing tissue binding of any autoantibody contained in the serum targeting antigens present in the substrates [11]. After washing to remove unbound antibodies, a second, fluorochrome labelled anti-human antibody is added, and, after re-washing, the substrates are examined by ultraviolet microscopy. Characteristic IIF staining patterns are given by positive sera, which should be titrated to extinction. Anti-nuclear reactivities should be further characterized on HEp2 cells, which, thanks to their large nuclei, allow detection of the nuclear IIF patterns, which are of crucial clinical importance in the setting of autoimmune liver diseases (see below).

The conventional starting serum dilution is $1: 10$. In adults, the positivity cut-off is $1: 40$, whereas in children and adolescents titres from 1:20 for ANA and SMA and from 1:10 for anti-LKM1 and for anti-LC1 are considered positive, since autoantibodies are rare in healthy subjects of these age groups [11].

Molecular assays are usually based on purified or recombinant antigens attached to a solid phase, to which diluted patient serum is added: if the corresponding antibody is present in the test serum, it will bind to the antigen-coated solid phase and is detected in a subsequent step by adding anti-human antibodies labelled with a chemiluminescent or fluorescent agent, or with an enzyme- or radio-label.

Of importance, anti-soluble liver antigen antibody (antiSLA), deemed to be the only AIH-specific reactivity, is undetectable by standard IIF, while it can be detected by solid phase assays, which should be part of the diagnostic work-up of every patient with acute or chronic liver disease [10].

\section{Anti-Nuclear Antibody}

Historically, ANA is the first autoantibody that has been associated to $\mathrm{AIH}$, therefore suggesting an autoimmune origin of the disease, at that time named "chronic hypergammaglobulinemic hepatitis" [15].

ANA should be tested by IIF, since nuclear target antigens in AIH are unknown in at least one third of the patients, leading to false negative results with potentially severe clinical consequences if only molecular-based tests are used [10] (Fig. 1). According to the recommendations issued by the IAIHG, HEp2 cells should not be used to investigate ANA at a screening level, since this substrate leads to potential false positive results, as low-titre positivity can be found in health $[16,17]$. Nevertheless, this recommendation, which relates to the clinical context of liver diseases, is nowadays 

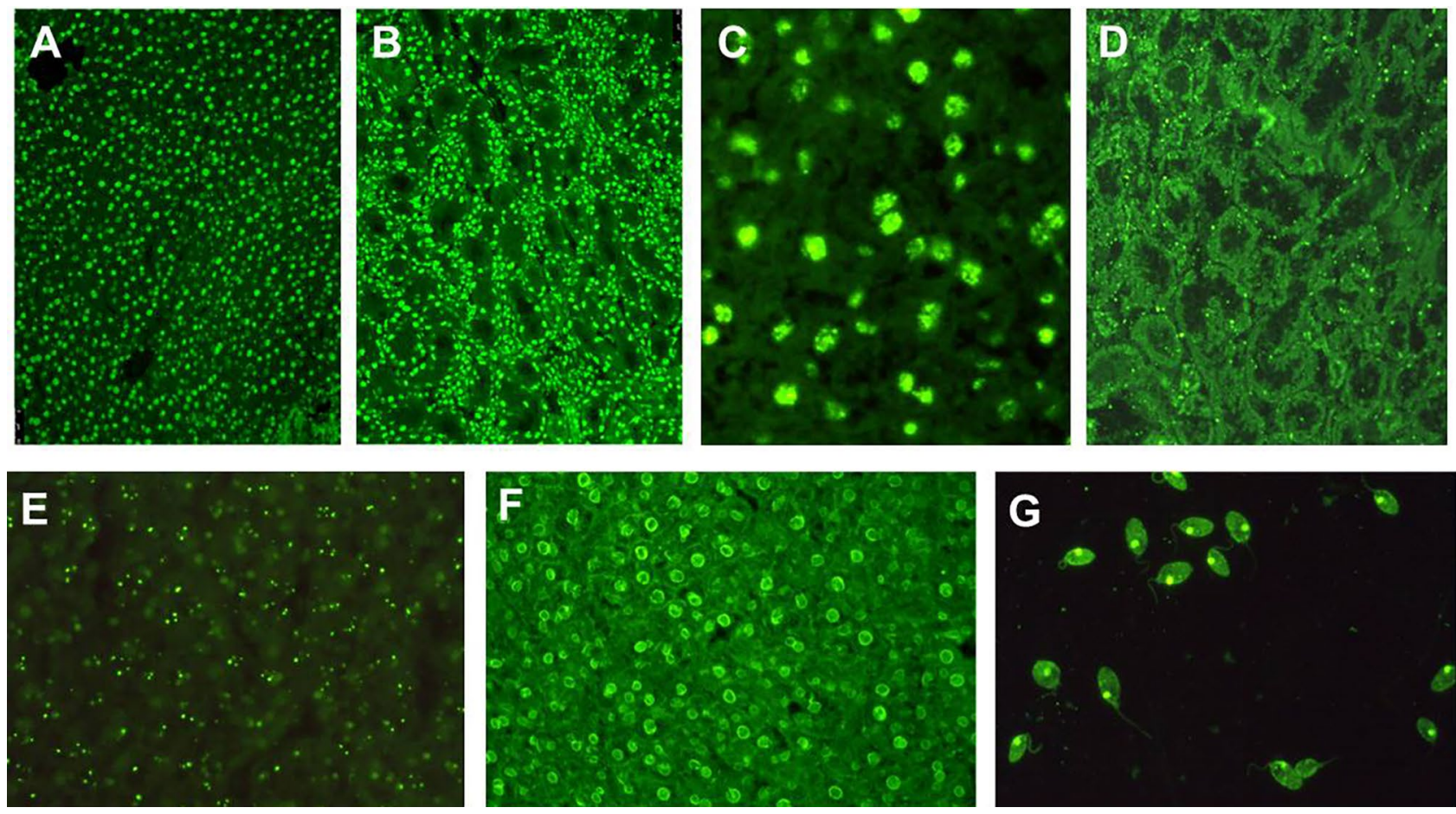

Fig. 1 Anti-nuclear antibodies (ANA) detected by indirect immunofluorescence. A ANA with homogeneous pattern on rodent liver. B ANA with homogeneous pattern on rodent kidney. C ANA with speckled pattern on rodent liver, visualized at higher magnification. Anti-nucleolar antibody on rodent kidney $\mathbf{D}$ and liver E. F Peripheral or rim-like ANA on rodent liver. G Anti double-stranded DNA

rarely followed by clinical laboratories, and HEp2 cells are widely used for ANA testing [18-20]. Therefore, HEp2 cells are used as a screening substrate also in the context of liver diseases, with a suggested higher positivity cut-off $\geq 1: 160$ [14]. The clinical performance of this approach needs to be validated in further studies. As mentioned above, HEp2 cells should be used to characterize the nuclear staining pattern of positive sera [11] (Fig. 2). Some three quarters of AIH patients show a homogeneous nuclear staining pattern on HEp2 cells, the remainder displaying a speckled or nucleolar pattern [10] (Fig. 2). Reported nuclear target antigens in AIH are listed in Table 1; among them, it should be mentioned that a strong association between anti-Ro52 and anti-SLA has been reported: therefore, anti-SLA should be tested in anti-Ro52-positive patients with liver disease [21]. Neither nuclear IIF patterns nor target antigens have been associated with specific clinical phenotypes to date [22].

ANA, coupled with SMA, defines AIH-1, being positive in about two thirds of the patients, associated with SMA in half of the cases [1,23]. Seronegative AIH is rare, $>95 \%$ of the cases being positive for ANA and/or SMA, provided that autoantibodies are tested according to recommended cut-offs [11]. The clinician should be aware that ANA lacks disease specificity, being detected staining the kinetoplast of the flagellate parasite Crithidia luciliae. The patterns most commonly found in autoimmune hepatitis type 1 are $\mathbf{A}$ and $\mathbf{B}$, followed by $\mathbf{C}$, and much less frequently $\mathbf{D}, \mathbf{E}$, and $\mathbf{F}$. Detection of anti-double stranded DNA on Crithidia luciliae has high specificity but low sensitivity

also in liver diseases different from AIH-1, particularly viral hepatitis B, C, D, and E, drug-induced liver injury, Wilson disease, alcohol-induced liver disease, and nonalcoholic fatty liver disease [24-28]. A variety of extrahepatic organ-specific and systemic autoimmune diseases are also typically associated with ANA-positivity, such as lupus erythematosus, Hashimoto thyroiditis, systemic sclerosis, or celiac disease, which may coexist with AIH [22]. Moreover, ANA may be positive even in healthy individuals, with frequency and titres increasing with age [16, 17].

Two ANA nuclear staining patterns are of particular clinical importance in the context of liver disease, i.e. the rim-like (also referred to as membranous) and the multiple-nuclear dot patterns (Fig. 2D, E), which, in association with a cholestatic biochemical profile, are characteristic of PBC, being particularly helpful in the diagnosis of AMAnegative $\mathrm{PBC}[12]$. The main target antigen of the latter reactivity is sp100, whereas the anti-rim like antibody targets mainly gp210; molecular tests are available using these antigens, which however are not the only targets of the rim-like and multiple nuclear dot ANA, since both the nuclear membrane and the nuclear bodies, stained by the anti-rim-like and the anti-multiple nuclear dots, respectively, are complex structures [10]. 
Fig. 2 Anti-nuclear antibodies (ANA) detected on HEp2 cells by indirect immunofluorescence. The large nuclei of this laryngeal tumour cell line allow clear visualization of the ANA patterns. A Homogeneous. B Speckled. C Nucleolar. D Multiple nuclear dots. E Rimlike. $\mathbf{A}$ and $\mathbf{B}$, and to a much lower frequency $\mathbf{C}$, are found in autoimmune hepatitis type $1, \mathbf{A}$ being by far the most common. $\mathbf{D}$ and $\mathbf{E}$ are patterns frequently encountered in primary biliary cholangitis
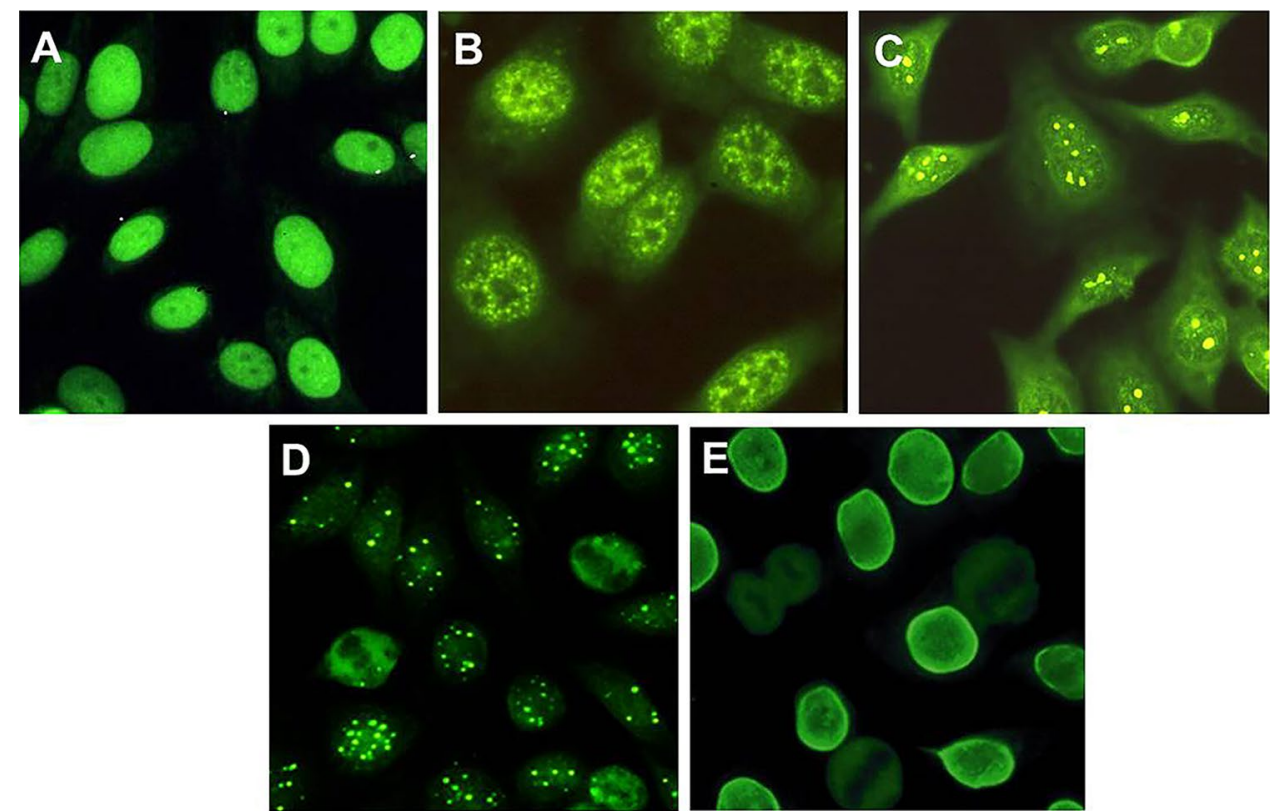

Clinical laboratories are increasingly reporting positive cytoplasmic and mitotic immunofluorescence reactivities on HEp2 cells, according to the recommendations by the Executive Committee of the International Consensus on Antinuclear Antibody Patterns (ICAP) [20]. However, some laboratories, using HEp2 cells as substrate, report cytoplasmic staining as ANA, generating confusion in the clinical setting. Only Jo-1, targeting histidyl-tRNA synthetase in myositis and antisynthetase syndrome, which gives both a nuclear and cytoplasmic granular staining, may be referred to as ANA [29, 30]. Thus, there is an open ongoing discussion among international experts on how to address this issue. In the context of AIH, the clinical significance of these patterns is unknown and urgently needs to be investigated. Moreover, reporting a positive cytoplasmic pattern as ANA positive may lead to an incorrect score within the IAIHG diagnostic systems [31, 32]. To add more complexity to this issue, AMA, which provides negative points in the revised AIH scoring system [31], gives a cytoplasmic IIF pattern on HEp2 cells. The new and semantically more appropriate suggested nomenclature of "anti-cell antibody" has not yet been widely accepted, due to the potential major impact of a nomenclature change on disease classification criteria, methodologic consensus, and reimbursement policies [33].

\section{Anti-Smooth Muscle and Anti-Actin Antibodies}

The description of anti-SMA in 1965 contributed significantly to discriminate AIH from lupus erythematosus, this reactivity being absent in the latter condition [34]. On triple rodent tissue, anti-SMA stains the smooth muscle of the muscularis mucosa of the gastric wall, but also the smooth muscle of the mesangium of renal glomeruli and arterial walls [26] (Fig. 3). Bottazzo et al. recognized in 1976 three distinct IIF staining patterns on kidney tissue, namely vessel (V), vessel glomerular (VG), and vessel glomerular tubular (VGT) patterns [35] (Fig. 3). While the $\mathrm{V}$ pattern was detected also in serum of patients with viral infections, drug-induced liver injury, malignancies, fatty liver disease, primary sclerosing cholangitis (PSC) and $\mathrm{PBC}$, the VG and VGT patterns were predominantly detected in serum of patients with $\mathrm{AIH}$, at that time referred to as chronic active hepatitis $[35,36]$. This association was validated in later studies [14, 37]. Therefore, clinical laboratory reports should include the IIF staining pattern of SMA-positive sera. The clinician, however, should be aware that some $20 \%$ of AIH SMA-positive patients lack the VG- or VGT-patterns, and, conversely, these patterns can be observed in liver diseases different from AIH, particularly viral hepatitis [10, 38]. The SMA titre is also of clinical significance, since higher titres have higher AIH-specificity [10, 27, 38]. If vascular smooth muscle cells (VSM) 47 cells, derived from rat embryonic thoracic aorta, are used as a substrate, sera giving the VGT pattern on kidney substrate give a typical cytoskeletal pattern (Fig. 3E). On a fibroblast substrate, these sera stain components of the cytoskeleton, giving the so called microfilament or F-actin pattern, suggesting that their antigenic target is an actin component [36, 37] (Fig. 3F). This observation led to the establishment of solid-phase assays using filamentous actin as an antigenic source, the results of which, however, are negative 


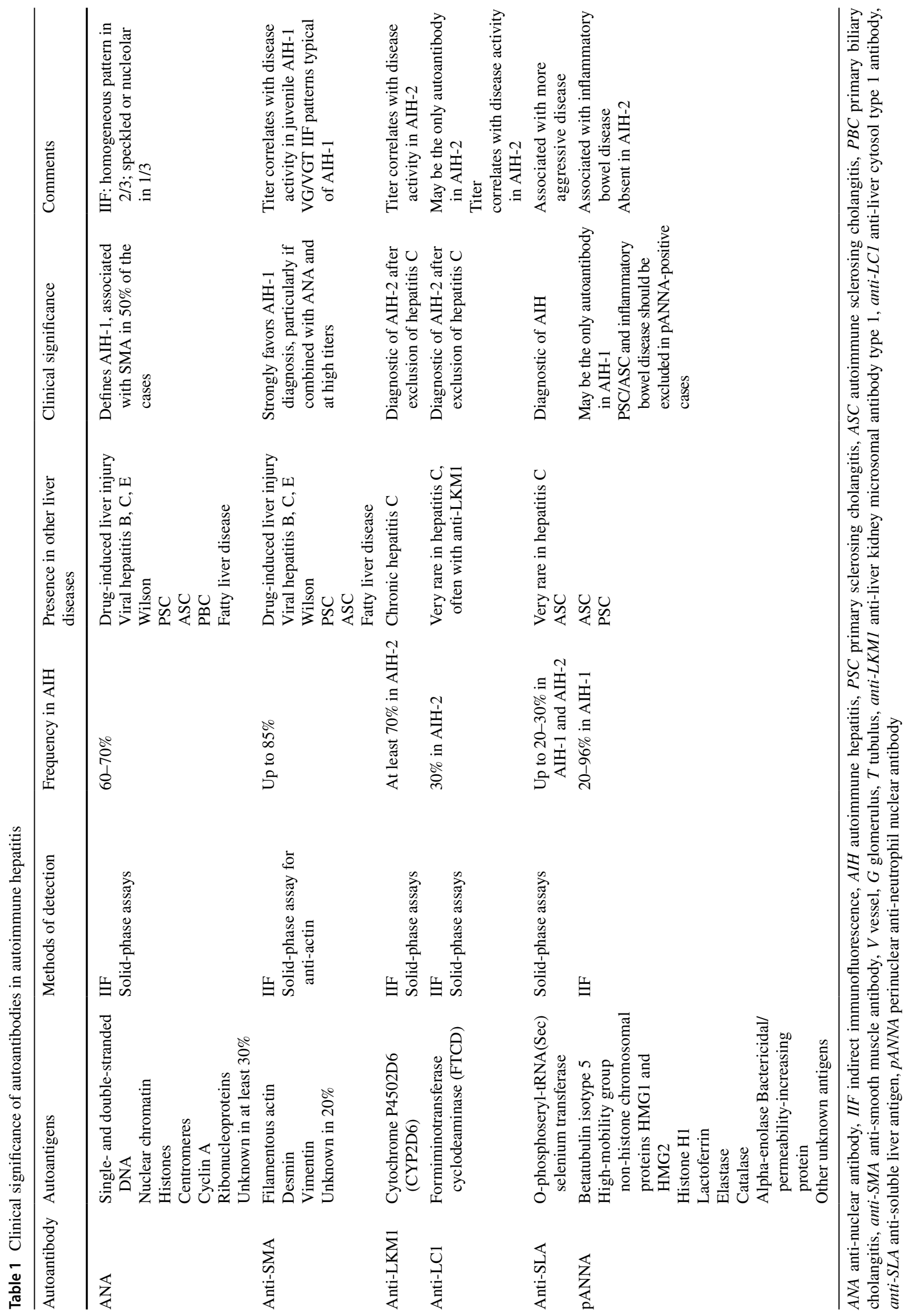



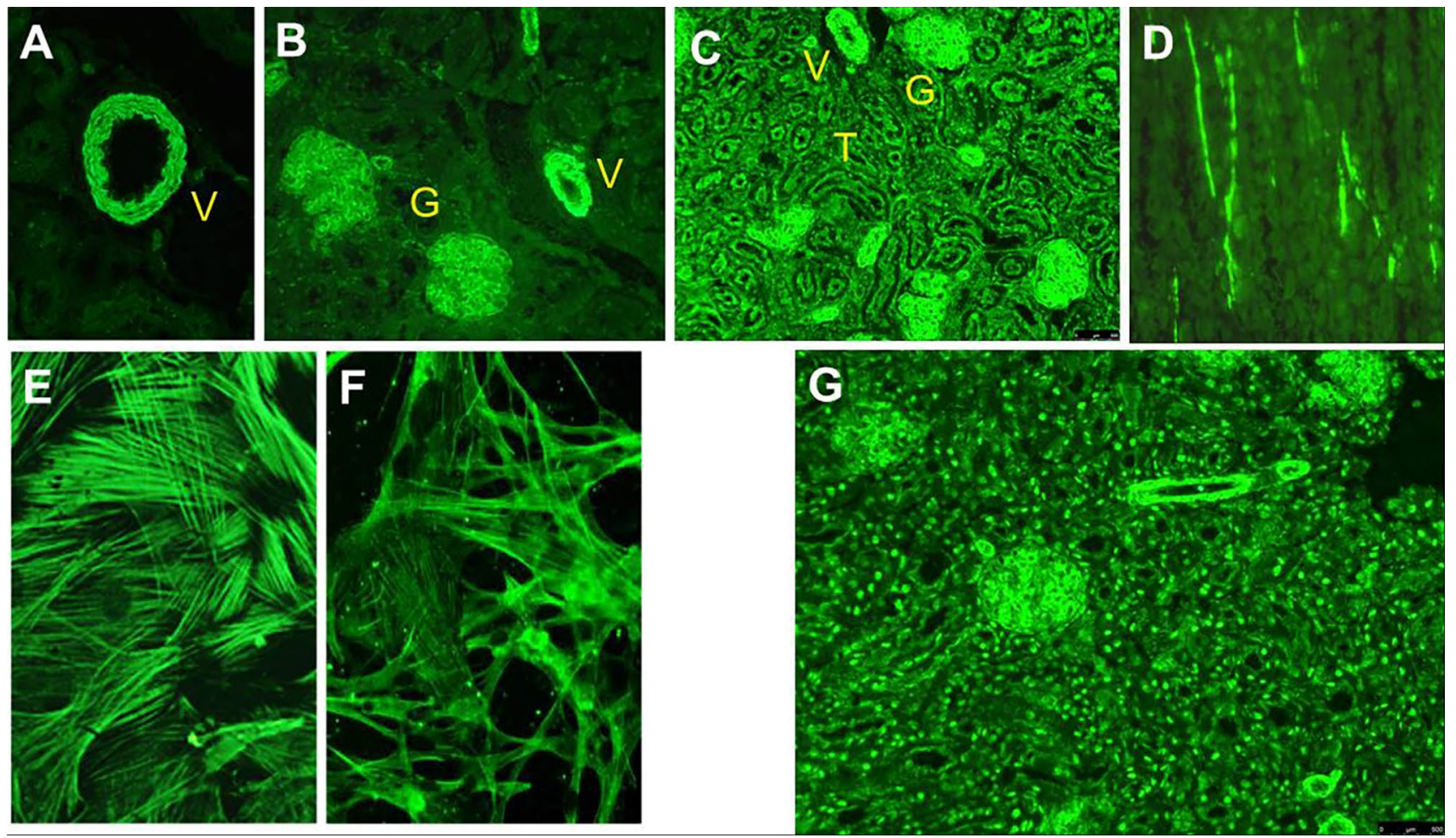

Fig. 3 Anti-smooth muscle antibodies (SMA) detected by indirect immunofluorescence. A, B, and $\mathbf{C}$ Rodent kidney substrate; $\mathbf{A}$ vascular pattern (V); B vascular and glomerular pattern (VG); C vascular, glomerular, and tubular pattern (VGT). D Rodent stomach: staining of smooth muscle fibres between the gastric glands. E Human fibro- blasts showing the so called "actin pattern" of SMA. F Vascular smooth muscle (VSM) 47 cells, also showing the "actin pattern." G Rodent kidney showing the simultaneous presence of SMA with VG pattern and homogeneous ANA in a patient with autoimmune hepatitis type 1 in some $20 \%$ of the VGT positive sera, indicating that additional, yet unknown, autoantigens are targeted by this reactivity, or, alternatively, that $\mathrm{B}$ cell epitopes are lost during protein purification $[11,36]$. Therefore, anti-actin molecular assays should be used in a complementary manner to IIF on triple rodent tissue. On the other hand, anti-actin positivity is rarely found in SMA-negative AIH sera [39]. Moreover, low-titre anti-actin antibody can be found in patients with non-AIH liver diseases, particularly $\mathrm{PBC}$ and chronic hepatitis $\mathrm{C}$, but are virtually absent in healthy controls [40, 41]. One study found an association of anti-actin antibody with more aggressive AIH [39].

In paediatrics, and possibly also in adults, SMA titres correlate with disease activity, and therefore are included in the definition of disease remission [42].

SMA, as mentioned before, defines AIH-1, being positive in $85 \%$ of the cases, associated with ANA in 50\% [10]. The same autoimmune serological profile is shared with the paediatric condition referred to as autoimmune sclerosing cholangitis (ASC), which represents an overlap of AIH with an autoimmune attack to intrahepatic and/or extrahepatic bile ducts [9, 43, 44].

\section{Anti-Liver-Kidney Microsomal Antibody}

Anti-LKM was discovered by Mario Rizzetto in 1973 in Deborah Doniach's laboratory in London. He identified in the serum of a small fraction of a large group of patients with liver diseases an autoantibody that gave a bright staining pattern of the hepatocyte cytoplasm and of the proximal renal tubuli [45] (Fig. 4). Since the reactivity was abolished after incubation of the serum with a "microsomal fraction" obtained by ultracentrifugation of liver homogenate, the autoantibody was named anti-LKM [46]. The liver disease associated with anti-LKM was fully characterized by Alagille's group in 1987 in Paris, who reported a cohort of 65 anti-LKM-positive patients, of whom $89 \%$ were female, and $56 \%$ were younger than 20 years, affected by an aggressive inflammatory liver disease, with a 14 -year survival of only $51 \%$ despite treatment with prednisone and azathioprine [47]. This severe condition affecting mainly children and adolescents was named AIH-2; ANA, SMA, and AMA were reportedly absent in AIH-2 patients [47]. 
Fig. 4 Anti-liver kidney microsomal type 1 (anti-LKM1) and anti-liver cytosol type 1 (antiLC1) antibodies detected by indirect immunofluorescence on rodent tissue. A Anti-LKM1 on liver and kidney: strong staining of the cytoplasm of hepatocytes and of large renal tubuli. B Anti-LC1 on liver: the fluorescence typically declines towards the central vein. C Anti-LKM1 on liver, when $\mathbf{B}$ and $\mathbf{C}$ occur simultaneously; anti-LC1 is masked by the strong fluorescence of anti-LKM1 and should be investigated by molecular assays
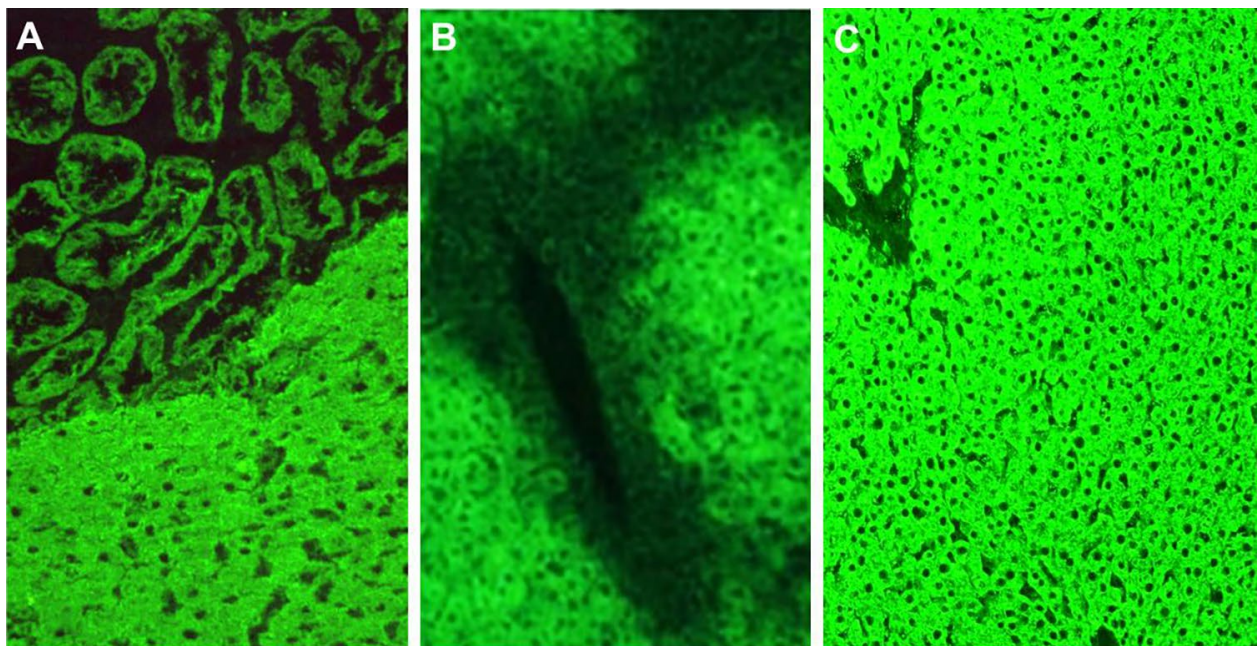

Anti-LKM1 is the serological hallmark of AIH-2, which is much rarer than $\mathrm{AIH}-1$, accounting for $20-30 \%$ of paediatric and for up to $10 \%$ of adult AIH cases [2, 9, 48, 49].

Anti-LKM1 may be misdiagnosed by IIF, as AMA, particularly if the stomach substrate, spared by anti-LKM1, is not used [50]. The subtle differences between the two reactivities on liver and kidney substrates require a trained observer: on kidney tissue, anti-LKM1 stains the proximal larger tubules, whereas AMA stains more brightly the smaller, mitochondriarich distal tubules; on liver tissue, the AMA staining pattern is much fainter as compared to the anti-LKM1 one [10, 22]. The identification of cytochrome P4502D6 (CYP2D6) as the target antigen of anti-LKM1 has allowed the establishment of reliable molecular-based assays, which allow to clarify doubtful cases [51-54]. Different immunodominant B-cell epitopes of this large protein have been subsequently identified, which are hierarchically recognized [55-57].

Anti-LKM1 titres correlate with disease severity in children with AIH-2 and should be used to monitor disease activity [42]. Furthermore, reappearance of anti-LKM1 antibody after liver transplantation for AIH-2 is associated with disease recurrence in the graft [58].

Anti-LKM1 is not entirely disease specific, being detected in up to $13 \%$ of patients with chronic hepatitis $\mathrm{C}$ infection [10, 38, 59]. The target epitopes of CYP2D6 of anti-LKM1 in AIH-2 and HCV show partial overlap, suggesting cross-reactivity between viral and self-epitopes [55, 60, 61]. Aminoacidic sequence homologies with CYP2D6 have been reported also for Cytomegalovirus and Herpes virus, leading to the "multiple hit hypothesis," which states that exposure to self-mimicking sequences present in multiple common viruses may trigger AIH-2 in genetically predisposed subjects [62]. This pathogenetic mechanism is well illustrated by the case of a girl developing AIH-2 after exposure to several viruses, whose antigens have epitopes mimicking CYP2D6 [63].

Anti-LKM with slightly different IIF patterns and different clinical significance have been reported. De novo $\mathrm{AIH}$, a disease entity indistinguishable from AIH arising in liver transplant recipients who underwent liver transplantation for diseases different from AIH, may be associated with an anti-LKM1 antibody giving an atypical IIF staining pattern, namely staining only kidney tissue, and referred to as atypical anti-LKM1 [64].

Anti-LKM2 has been identified in serum of patients with hepatitis induced by ticrynafen, also named tielinic acid, an uricosuric and anti-hypertensive drug withdrawn from the market in 1982 owing to its hepatotoxicity [46, 65]. This specificity, that targets CYP2C9, stains liver tissue in a inhomogeneous pattern, with more intense staining of the centrilobular hepatocytes; on kidney substrate, it stains preferentially the first and second portions of the proximal tubuli [66-68]. Anti-LKM3 has been detected in 13\% of patients with chronic hepatitis delta by Crivelli et al. [69]. Its target antigen is family 1 uridine 5 '-diphosphate glucuronosyltransferase (UGT-1). Anti-LKM3 needs to be tested on human or primate substrate, where it stains hepatocyte cytoplasm and proximal renal tubuli [70, 71]. Of note, antiLKM3 has been found also in 19\% of AIH-2 patients, rarely being the only serological marker [70].

Autoimmune polyendocrinopathy-candidiasis-ectodermal dystrophy (APECED) is a rare autosomal recessive disorder associated with mutations in the autoimmune regulator gene (AIRE), with some $20 \%$ of the patients affected also by an anti-LKM1-positive hepatitis [72]. Although the target antigens are CYP2A6 and CYP1A2, the IIF staining pattern on triple tissue is indistinguishable from $\mathrm{AIH}-2$-associated anti-LKM1 [73]. 


\section{Anti-Liver Cytosol Type 1}

Anti-LC1 antibody was first reported by Martini et al. in 1988, who identified it in serum of 21 patients with juvenile hepatitis, being the only serological marker in seven of them, and associated with anti-LKM1 in the remainder [74]. This early study already highlighted the diseasespecificity of anti-LC1, which was absent in a large number of pathological and healthy controls [74]. The clinical features of AIH-2 anti-LC1-positive patients are indistinguishable from patients without this antibody [74]. On rodent liver substrate, this organ-specific reactivity stains brightly the hepatocyte cytoplasm, sparing the centrilobular zone [27] (Fig. 4). It can be masked by concomitant anti-LKM1 (Fig. 4), the two autoantibodies being often present in the same patient, making the commercial availability of reliable solid-phase assays very helpful [10]. Indeed, the target antigen of anti-LC1 has been identified as the formiminotransferase cyclodeaminase (FTCD), an intracellular enzyme catalyzing the conversion of histidine to glutamic acid [75, 76].

Anti-LC1, together with anti-LKM1, defines AIH-2. In about two-thirds of the cases, the two autoantibodies coexist, but in some patients, anti-LC1 is the only serological marker, making it essential for it to be investigated [23, 42, 74]. Anti-LC1 is very rarely detected in HCV patients, usually in association with anti-LKM1, and in patients with AIH-1 or ASC [77-79].

\section{Anti-Soluble Liver Antigen Antibody}

Peter Berg in 1981 in Germany identified by complement fixation test an antibody in the serum of 20 patients with liver disease (18 female) reacting with the supernatant of rodent liver and pancreas homogenate, which he named anti-liver-pancreas (LP) antibody [80]. Response to prednisone treatment, \pm azathioprine, was satisfactory in this small cohort of patients [80]. Some years later, the same group suggested that this specificity characterizes a distinct subgroup of AIH, namely type 3 AIH [81, 82]. Michael Manns in 1987 detected in the serum of 23 patients, mostly young women, an antibody recognizing an antigen contained in the supernatant of liver homogenate, which he called anti-soluble liver antigen (anti-SLA) [83]. AntiSLA positive patients suffered from an aggressive form of hypergammaglobulinemic hepatitis, with good response to immunosuppressive treatment [83]. Since this reactivity was the only serological marker in $6 / 23$ patients, also Manns suggested that it defines a third AIH subtype [83]. This suggestion was subsequently not approved by the IAIHG, since the sera in Manns' paper had been tested using an ANA cut-off positivity higher than that recommended by the international AIH community [10]. Indeed, if tested at the recommended cut-off of 1:40, AIH patients with isolated anti-SLA positivity are rare [11]. Several years after the reports by Berg and Manns, it was recognized that anti-LP and anti-SLA are the same antibody, which is nowadays referred to as anti-SLA [25]. Of importance, anti-SLA is undetectable by immunofluorescence [22].

Anti-SLA is the only AIH-specific autoantibody, with a reported disease specificity as high as $98.9 \%$, and has therefore a high value in the simplified IAIHG scoring system [1, $32,78]$. However, it is detected in only $20-30 \%$ of patients using commercially available solid-phase assays [10]. If sensitive radioligand assays are used, up to two-thirds of AIH patients are anti-SLA positive [84]. Of interest, anti-SLA is seen in both AIH-1 and AIH-2, a feature that, coupled with its high disease specificity, suggests a key pathophysiological role of its antigenic target, i.e. the intracellular enzyme O-phosphoseryl-tRNA(Sec) selenium transferase (SEPSECS), required for selenoprotein biosynthesis, originally identified by Gelpí in 1992, and later confirmed by Wies and by Volkmann as the molecular target of anti-SLA [85-88]. The reason why anti-SLA has low sensitivity in AIH is probably that molecular-based assays used in clinical laboratories only detect antibodies reacting with linear epitopes since they contain prokaryotically expressed antigens. Assays using eukaryotically expressed SEPSECS are cumbersome and still not suitable for clinical use. Epitope mapping of anti-SLA, using prokaryotically expressed protein, identified SEPSECS 395-414 as the immunodominant B cell epitope, overlapping with one HLA DRB1*0301restricted T cell epitope $[89,90]$.

Besides being highly specific for AIH, anti-SLA is associated with more aggressive disease, namely more severe histology, longer time to achieve disease remission, more frequent relapse and need for liver transplantation, and death [84]. A recent study confirmed that anti-SLA positive AIH patients more often require lifelong immunosuppression, need longer time to achieve disease remission, and can less frequently be weaned from corticosteroid treatment as compared to anti-SLA-negative patients [91].

\section{Anti-Neutrophil Cytoplasmic Antibody}

Anti-neutrophil cytoplasmic antibody (ANCA) has been first reported in the context of small- and medium-sized vessel vasculitis $[92,93]$. It is detected by IIF on fixed human neutrophilic granulocytes, where different staining patterns are possible: cANCA display a diffuse cytoplasmic granular fluorescence, and pANCA display a perinuclear, often with 
nuclear extension, fluorescence [10]. While granulomatosis with polyangiitis is typically associated with cANCA, microscopic polyangiitis and eosinophilic granulomatosis are characterized by positive pANCA [94]. Both cANCA and pANCA target cytoplasmic proteins, the pANCA staining pattern being an artefact due to ethanol fixation of the neutrophils, which leads to migration of positively charged cytoplasmic proteins to the negatively charged nuclear cell membrane. Therefore, both ethanol and formalin-fixed neutrophils should be used to investigate ANCA. If the staining pattern is unaffected by ethanol fixation, the antibody is referred to as atypical pANCA, which targets components of the cell nuclear membrane, explaining its designation as perinuclear anti-neutrophil nuclear antibody (pANNA) [95] (Fig. 5). An alternative name for the same reactivity is nuclear anti-neutrophil antibody (NANA) [10]. The presence of ANA in the same serum may hinder pANCA detection owing to nuclear staining by ANA. As the main target antigen of cANCA is cytoplasmic protein leukocyte proteinase 3 , and pANCA recognizes myeloperoxidase, molecularbased assays are commercially available for both [96]. This is not the case for pANNA, whose target antigens are only partially known, and in AIH-1 reportedly include betatubulin isotype 5, the high-mobility group non-histone chromosomal proteins HMG1 and HMG2, histone H1, lactoferrin, elastase, catalase, enolase, and bactericidal/permeabilityincreasing protein [96-98]. Interestingly, cross-reactivity of pANNA with betatubulin isotype 5 and the bacterial cell division protein FtsZ has been reported in PSC and AIH, suggesting a pathogenetic role of bacteria in these conditions [99].

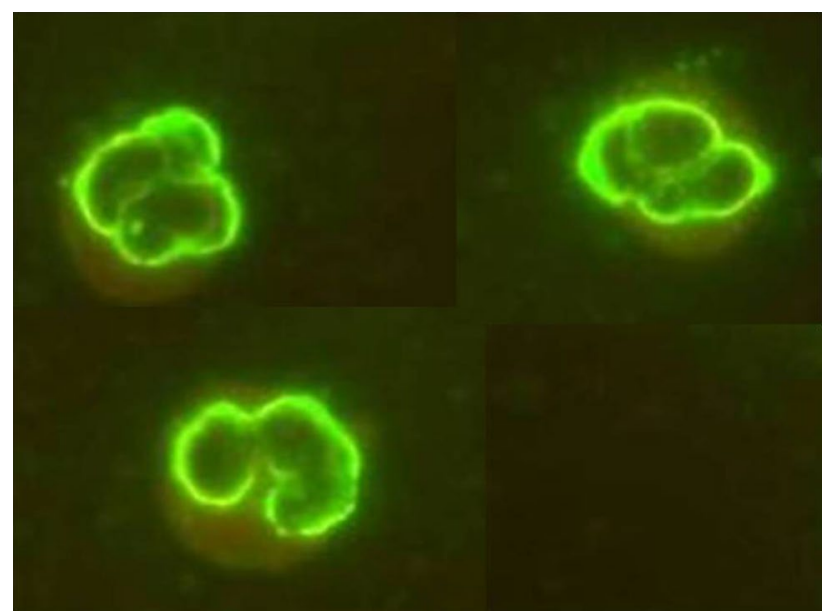

Fig. 5 Anti-neutrophil cytoplasmic antibody with perinuclear pattern (pANCA), also known as perinuclear anti-neutrophil nuclear antibody (pANNA) detected by indirect immunofluorescence on human neutrophilic granulocytes. pANNA may be the only autoantibody present in autoimmune hepatitis type 1 , though it is more frequently found in sclerosing cholangitis and inflammatory bowel disease (see text)
Reported frequency of pANNA in AIH-1 ranges from 40 to $96 \%$, being the only serological marker in a small subgroup of AIH-1 patients: therefore, it should be tested in patients with suspected AIH-1 and negative ANA, SMA, and anti-SLA $[10,100,101]$. cANCA is rare in AIH-1. In AIH-2, ANCA is virtually absent [10].

Besides AIH-1, ANCA is commonly found in PSC, with a reported frequency of up to $94 \%$ [102]. In children, ANCA frequency is higher in ASC as compared to AIH-1 [9]. Besides AIH, PSC, and ASC, pANNA is found in up to $80 \%$ of patients with inflammatory bowel disease [103]. Due to the association of $\mathrm{AIH}$ with sclerosing cholangitis and inflammatory bowel disease, we suggest that ANCA-positive AIH patients, particularly those with juvenile $\mathrm{AIH}$, are screened for concomitant bile duct and bowel disease [43].

\section{Diagnostic Approach to the Patient with Suspected Autoimmune Hepatitis}

While autoantibodies are an essential tool in the diagnostic jigsaw puzzle of AIH, they are not diagnostic on their own. Therefore, an essential knowledge of their testing methodologies and clinical significance is mandatory to use them correctly in clinical practice.

AIH should be considered in the differential diagnosis of every patient, of whatever age, presenting with liver disease of unknown origin, since AIH initial presentation is highly heterogeneous, ranging from asymptomatic to acute liver failure (see above) [1]. In addition to autoantibodies and serum IgG, liver histology is needed to confirm the diagnosis and to evaluate the severity of liver damage: interface hepatitis is the histological hallmark of AIH, but it is not pathognomonic, being found in other inflammatory liver diseases including viral hepatitis and Wilson disease. In acutely presenting $\mathrm{AIH}$, and during relapses, panlobular hepatitis with centrilobular and bridging necrosis are often seen. In addition, liver histology is mandatory to diagnose $\mathrm{PBC}$ and PSC variant syndromes in adults, and ASC in children.

Autoimmune serological workup (Fig. 6) should include IIF on triple rodent tissue and a solid-phase assay for antiSLA [4]. This approach allows the detection of the majority of liver-related autoantibodies, i.e. ANA, SMA, anti-LKM1, anti-LC1, AMA, and anti-SLA. Combined positivity of ANA and SMA in the appropriate clinical context is highly suggestive of AIH-1, particularly if the SMA IIF pattern on kidney substrate is VG or VGT (Fig. 3). Anti-actin can be used as confirmatory test of SMA, or to exclude a rare anti-actin-positivity in the absence of SMA. Positive antiLKM1 and/or anti-LC1 strongly suggest the diagnosis of AIH-2. AMA suggest PBC variant syndrome; however, AMA can transiently be positive in acute liver failure [104]. As mentioned above, isolated anti-SLA positivity is rare but 
Fig. 6 Summary of the clinical associations of autoantibodies in autoimmune hepatitis type 1 and type 2

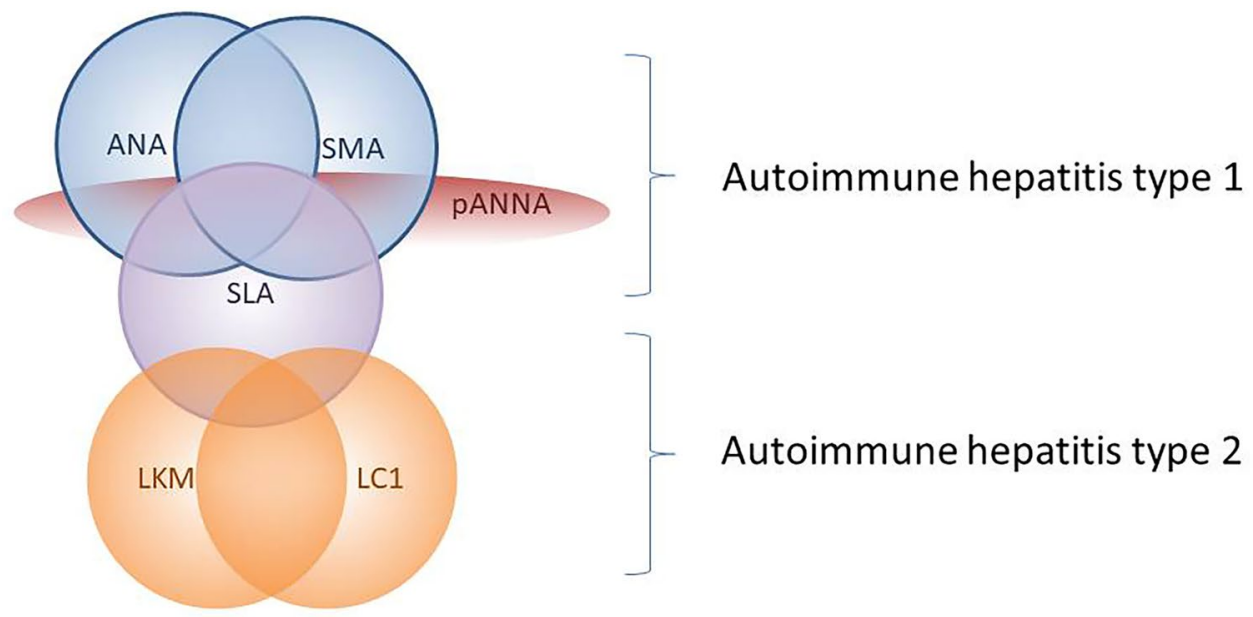

possible in AIH-1. If this first set of autoantibodies does not show positive reactivities, ANCA should be tested using human neutrophils, since this autoantibody may be the only autoantibody present in a small subgroup of AIH-1 patients [10]. In juvenile AIH and ASC, autoantibodies should be used also to monitor disease progression, since titres correlate with disease activity [42]. A Brazilian study found that SMA titres correlate with disease activity also in adults with AIH-1, but further validation is needed before this can be included in the criteria of biochemical remission in the adult population [105].

\section{Reflections on Autoantibody Testing and Conclusion}

Indirect immunofluorescence is an old technique requiring expertise and patience that may not be ideal for the modern laboratory. Yet, for the moment, it is here to stay.

Case number 5 of the Massachusetts General Hospital (MGH), published in 2009, is especially instructive and relevant to autoantibody testing [106]. It describes "A 47-Year-Old Woman with a Rash and Numbness and Pain in the Legs." The patient had been suffering from pain and swelling of her legs, tender nodules, dry eyes and numbness, tingling, and colour changes in her fingers, for approximately 2 years. After physical examination and evaluation of her tests, Dr D Kroshinsky summed up: "This patient presents with a rash compatible with livedo reticularis, tender cutaneous nodules, atrophie blanche, mononeuritis multiplex, and peripheral-blood cytopenias. Serologic testing for rheumatologic diseases has been unrevealing." The rheumatologist, Dr J H Stone, who examined the patient on admission at MGH, was asked for his possible diagnoses. The one he put on the top of the list was ANA negative systemic lupus erythematosus (SLE), noting that during the previous 2 years, ANA and anti-ds DNA were tested twice and resulted negative. He was puzzled since ANA is present in up to $99 \%$ of SLE patients and ordered new serologic tests. Indirect IIF on HEp2 cells showed an ANA positive at a titre of 1:1280. A repeat test was also positive. Could the patient have developed ANA over the 8 weeks before being seen at the Bostonian centre of excellence? The highly positive ANA sample on IIF was then sent to the commercial laboratory that had tested the patient's sera previously. It was found to be negative. The technique unable to detect such a high titre ANA was flow cytometry-based solid-phase screening assay, in which coloured polystyrene beads coated with autoantigens are mixed with the patient's serum, incubated with fluorescein conjugated antihuman $\mathrm{IgG}$, and examined with the use of a dual-laser flow cytometer to detect both the colour of the bead and the amount of autoantibody coating the bead. The flow cytometry-based kit contains nine different-coloured beads coated with defined autoantigens: Ro, La, Sm, U1-RNP, Scl-70, Jo-1, Cenp-B, dsDNA, and histones. Importantly, a 10th bead is coated with material extracted from HEp-2 cell nuclei. This is a good example of how highly sophisticated tests, often advocated to replace old techniques, such as IIF, simply may not work.

Following this report and the fact that members of the American College of Rheumatology (ACR) were made aware of other inaccurate results for ANA testing, the College set up a Task Force to "evaluate the extent of the problem and to recommend solutions." The Task Force reviewed the relevant literature and concluded that solid phase immunoassays may not be appropriate for replacing IIF as a screening test for the detection of ANA [19]. The key recommendations of the Task Force were that, first, IIF 
ANA test should remain the gold standard for ANA testing and, second, that hospital and commercial laboratories using bead-based multiplex platforms or other solid phase assays for detecting ANA must provide data that their assay has the same or improved sensitivity and specificity as IIF ANA.

More recently Pisetsky, in an Opinion published in Nature Reviews/Rheumatology [107], wonders whether: "Antinuclear antibody testing is misunderstood or misbegotten?" Misbegotten, as per the Cambridge dictionary, relates to something "badly or stupidly planned or designed." Pisetsky reminds us that the nuclear antigens targeted by ANAs are usually present in the cell nucleus, though some may translocate to the cytoplasm, and that the HEp- 2 cell line is used for ANA testing in IIF because this cell line displays a wide variety of antigens. HEp-2 cell testing for ANA is indeed recommended as gold standard by the ACR. Pisetsky, however, notes that "unfortunately, the gold standard does not have the brightness and lustre often ascribed to it" since "IIF can be subject to variability related to the assay kit used, conditions of cell fixation, cellular concentration of antigens and the specificity of the anti-IgG reagents." Other issues raised are the initial dilution of the sample and the need for an expert observer. These limitations of the IIF technique have led to an interest in developing assays that might detect ANA more reliably, provide a higher throughput, in association to a decrease demand for experienced personnel and a higher cost efficiency. Pisetsky's review of the available observer-independent assays, however, did not fare particularly well. ELISAs detect antibody of low avidity, while multiplex assays may provide results that require confirmation by IIF. Moreover, at variance with IIF, antigens bound to the inert support in the solid phase immunochemical tests tend to lose conformational epitopes, arguably the most relevant targets of disease specific, possibly pathogenic, autoantibodies.

In conclusion, to date, the least misbegotten test for the detection of ANA remains indirect IIF on tissue or cell lines, and this applies to the other autoantibodies relevant to autoimmune liver disease. The outstanding issue is standardization, both for IIF and immunochemical assays, and efforts in this direction are currently ongoing at international level. An associated corollary is the need of not losing the expertise in "reading immunofluorescence," a prerogative belonging to a dwindling number of professionals, at least until artificial intelligence can do equally well or better than trained human eyes.

Funding Open Access funding provided by Università della Svizzera italiana.

\section{Declarations}

Conflict of Interest The authors declare no competing interests.

Open Access This article is licensed under a Creative Commons Attribution 4.0 International License, which permits use, sharing, adaptation, distribution and reproduction in any medium or format, as long as you give appropriate credit to the original author(s) and the source, provide a link to the Creative Commons licence, and indicate if changes were made. The images or other third party material in this article are included in the article's Creative Commons licence, unless indicated otherwise in a credit line to the material. If material is not included in the article's Creative Commons licence and your intended use is not permitted by statutory regulation or exceeds the permitted use, you will need to obtain permission directly from the copyright holder. To view a copy of this licence, visit http://creativecommons.org/licenses/by/4.0/.

\section{References}

1. Mieli-Vergani G, Vergani D, Czaja AJ et al (2018) Autoimmune hepatitis. Nat Rev Dis Primers 4:18017. https://doi.org/10.1038/ nrdp. 2018.17

2. Liberal R, Grant CR, Mieli-Vergani G, Vergani D (2013) Autoimmune hepatitis: a comprehensive review. J Autoimmun 41:126139. https://doi.org/10.1016/j.jaut.2012.11.002

3. Lv T, Li M, Zeng N et al (2019) Systematic review and metaanalysis on the incidence and prevalence of autoimmune hepatitis in Asian, European, and American population. J Gastroenterol Hepatol 34:1676-1684. https://doi.org/10.1111/jgh.14746

4. European Association for the Study of the Liver (2015) EASL Clinical practice guidelines: autoimmune hepatitis. J Hepatol 63:971-1004. https://doi.org/10.1016/j.jhep.2015.06.030

5. Mack CL, Adams D, Assis DN et al (2020) Diagnosis and management of autoimmune hepatitis in adults and children: 2019 practice guidance and guidelines from the american association for the study of liver diseases. Hepatology 72:671-722. https:// doi.org/10.1002/hep.31065

6. Soloway RD, Summerskill WH, Baggenstoss AH et al (1972) Clinical, biochemical, and histological remission of severe chronic active liver disease: a controlled study of treatments and early prognosis. Gastroenterology 63:820-833

7. Murray-Lyon IM, Stern RB, Williams R (1973) Controlled trial of prednisone and azathioprine in active chronic hepatitis. Lancet $1: 735-737$

8. Cook GC, Mulligan R, Sherlock S (1971) Controlled prospective trial of corticosteroid therapy in active chronic hepatitis. Q J Med 40:159-185

9. Di Giorgio A, Hadzic N, Dhawan A et al (2020) Seamless management of juvenile autoimmune liver disease: long-term medical and social outcome. J Pediatr 218:121-129.e3. https://doi.org/ 10.1016/j.jpeds.2019.11.028

10. Terziroli Beretta-Piccoli B, Mieli-Vergani G, Vergani D (2018) The clinical usage and definition of autoantibodies in immunemediated liver disease: a comprehensive overview. J Autoimmun. https://doi.org/10.1016/j.jaut.2018.10.004

11. Vergani D, Alvarez F, Bianchi FB et al (2004) Liver autoimmune serology: a consensus statement from the committee for autoimmune serology of the International Autoimmune Hepatitis Group. J Hepatol 41:677-683. https://doi.org/10.1016/j.jhep. 2004.08.002

12. Terziroli Beretta-Piccoli B, Mieli-Vergani G, Vergani D et al (2019) The challenges of primary biliary cholangitis: what is 
new and what needs to be done. J Autoimmun 102328. https:// doi.org/10.1016/j.jaut.2019.102328

13. Gatselis N, Zachou K, Montano-Loza A et al (2020) Antimitochondrial antibodies in patients with autoimmune hepatitis: a large multicenter study. J Hepatol 73:S471. https://doi.org/10. 1016/S0168-8278(20)31423-9

14. Galaski J, Weiler-Normann C, Schakat M et al (2021) Update of the simplified criteria for autoimmune hepatitis: evaluation of the methodology for immunoserological testing. J Hepatol 74:312-320. https://doi.org/10.1016/j.jhep.2020.07.032

15. IanR M, Taft LI, Cowling DC (1956) Lupoid hepatitis. The Lancet 268:1323-1326. https://doi.org/10.1016/S0140-6736(56) 91483-0

16. Tan EM, Feltkamp TEW, Smolen JS et al (1997) Range of antinuclear antibodies in "healthy" individuals. Arthritis Rheum 40:1601-1611. https://doi.org/10.1002/art.1780400909

17. Hilário MOE, Len CA, Roja SC et al (2004) Frequency of antinuclear antibodies in healthy children and adolescents. Clin Pediatr (Phila) 43:637-642. https://doi.org/10.1177/000992280404300709

18. Buchner C, Bryant C, Eslami A, Lakos G (2014) Anti-nuclear antibody screening using HEp-2 cells. JoVE 51211. https://doi. org/10.3791/51211

19. Meroni PL, Schur PH (2010) ANA screening: an old test with new recommendations. Ann Rheum Dis 69:1420-1422. https:// doi.org/10.1136/ard.2009.127100

20. Andrade LEC, Klotz W, Herold M et al (2018) International consensus on antinuclear antibody patterns: definition of the AC-29 pattern associated with antibodies to DNA topoisomerase I. Clin Chem Lab Med. https://doi.org/10.1515/ cclm-2018-0188

21. Schramm C, Herkel J, Beuers U et al (2006) Pregnancy in autoimmune hepatitis: outcome and risk factors. Am J Gastroenterol 101:556-560. https://doi.org/10.1111/j.1572-0241. 2006.00479.x

22. Liberal R, Mieli-Vergani G, Vergani D (2013) Clinical significance of autoantibodies in autoimmune hepatitis. J Autoimmun 46:17-24. https://doi.org/10.1016/j.jaut.2013.08.001

23. Villalta D, Girolami E, Alessio MG et al (2016) Autoantibody profiling in a cohort of pediatric and adult patients with autoimmune hepatitis. J Clin Lab Anal 30:41-46. https://doi.org/10. 1002/jcla.21813

24. Dalekos GN, Gatselis NK, Zachou K, Koukoulis GK (2020) NAFLD and autoimmune hepatitis: do not judge a book by its cover. Eur J Intern Med 75:1-9. https://doi.org/10.1016/j.ejim. 2020.02.001

25. Sebode M, Weiler-Normann C, Liwinski T, Schramm C (2018) Autoantibodies in autoimmune liver disease-clinical and diagnostic relevance. Front Immunol 9:609. https://doi.org/10.3389/ fimmu.2018.00609

26. Bogdanos DP, Mieli-Vergani G, Vergani D (2009) Autoantibodies and their antigens in autoimmune hepatitis. Semin Liver Dis 29:241-253. https://doi.org/10.1055/s-0029-1233533

27. Bogdanos D-P, Invernizzi P, Mackay I-R, Vergani D (2008) Autoimmune liver serology: current diagnostic and clinical challenges. World J Gastroenterol 14:3374-3387

28. Terziroli Beretta-Piccoli B, Ripellino P, Gobbi C et al (2018) Autoimmune liver disease serology in acute hepatitis $\mathrm{E}$ virus infection. J Autoimmun. https://doi.org/10.1016/j.jaut.2018.07. 006

29. Vázquez-Abad D, Carson JH, Rothfield N (1996) Localization of histidyl-tRNA synthetase (Jo-1) in human laryngeal epithelial carcinoma cell line (HEp-2 cells). Cell Tissue Res 286:487-491. https://doi.org/10.1007/s004410050718

30. Gomard-Mennesson E, Fabien N, Cordier J-F et al (2007) Clinical significance of anti-histidyl-tRNA synthetase (Jo1) autoantibodies. Ann NY Acad Sci 1109:414-420. https://doi. org/10.1196/annals.1398.047

31. Alvarez F, Berg PA, Bianchi FB et al (1999) International Autoimmune Hepatitis Group Report: review of criteria for diagnosis of autoimmune hepatitis. J Hepatol 31:929-938

32. Hennes EM, Zeniya M, Czaja AJ et al (2008) Simplified criteria for the diagnosis of autoimmune hepatitis. Hepatology 48:169176. https://doi.org/10.1002/hep.22322

33. Damoiseaux J, von Mühlen CA, Garcia-De La Torre I et al (2016) International consensus on ANA patterns (ICAP): the bumpy road towards a consensus on reporting ANA results. Auto Immun Highlights 7:1. https://doi.org/10.1007/s13317-016-0075-0

34. Johnson GD, Holborow EJ, Glynn LE (1965) Antibody to smooth muscle in patients with liver disease. Lancet 2:878-879

35. Bottazzo GF, Florin-Christensen A, Fairfax A et al (1976) Classification of smooth muscle autoantibodies detected by immunofluorescence. J Clin Pathol 29:403-410

36. Beretta-Piccoli BT, Mieli-Vergani G, Vergani D (2017) Serology in autoimmune hepatitis: a clinical-practice approach. Eur J Intern Med. https://doi.org/10.1016/j.ejim.2017.10.006

37. Muratori P, Muratori L, Agostinelli D et al (2002) Smooth muscle antibodies and type 1 autoimmune hepatitis. Autoimmunity 35:497-500

38. Cassani F, Cataleta M, Valentini P et al (1997) Serum autoantibodies in chronic hepatitis C: comparison with autoimmune hepatitis and impact on the disease profile. Hepatology 26:561-566. https://doi.org/10.1002/hep.510260305

39. Czaja AJ, Cassani F, Cataleta M et al (1996) Frequency and significance of antibodies to actin in type 1 autoimmune hepatitis. Hepatology 24:1068-1073. https://doi.org/10.1002/hep.510240515

40. Liaskos C, Bogdanos D-P, Davies ET, Dalekos GN (2007) Diagnostic relevance of anti-filamentous actin antibodies in autoimmune hepatitis. J Clin Pathol 60:107-108. https://doi.org/10. 1136/jcp.2006.039404

41. Granito A, Muratori L, Muratori P et al (2006) Antibodies to filamentous actin (F-actin) in type 1 autoimmune hepatitis. J Clin Pathol 59:280-284. https://doi.org/10.1136/jcp.2005.027367

42. Mieli-Vergani G, Vergani D, Baumann U et al (2017) Diagnosis and management of paediatric autoimmune liver disease: ESPGHAN hepatology committee position statement. J Pediatr Gastroenterol Nutr. https://doi.org/10.1097/MPG.0000000000001801

43. Beretta-Piccoli BT, Vergani D, Mieli-Vergani G (2018) Autoimmune sclerosing cholangitis: evidence and open questions. J Autoimmun. https://doi.org/10.1016/j.jaut.2018.10.008

44. Gregorio GV, Portmann B, Karani J et al (2001) Autoimmune hepatitis/sclerosing cholangitis overlap syndrome in childhood: a 16-year prospective study. Hepatology 33:544-553. https://doi. org/10.1053/jhep.2001.22131

45. Rizzetto M, Swana G, Doniach D (1973) Microsomal antibodies in active chronic hepatitis and other disorders. Clin Exp Immunol 15:331-344

46. Smith MG, Williams R, Walker G et al (1974) Hepatic disorders associated with liver-kidney microsomal antibodies. Br Med J $2: 80-84$

47. Homberg JC, Abuaf N, Bernard O et al (1987) Chronic active hepatitis associated with antiliver/kidney microsome antibody type 1: a second type of "autoimmune" hepatitis. Hepatology 7:1333-1339

48. Floreani A, Franceschet I, Cazzagon N et al (2015) Extrahepatic autoimmune conditions associated with primary biliary cirrhosis. Clin Rev Allergy Immunol 48:192-197. https://doi.org/10.1007/ s12016-014-8427-x

49. Gregorio GV, Portmann B, Reid F et al (1997) Autoimmune hepatitis in childhood: a 20-year experience. Hepatology 25:541547. https://doi.org/10.1002/hep.510250308 
50. Czaja AJ, Manns MP, Homburger HA (1992) Frequency and significance of antibodies to liver/kidney microsome type 1 in adults with chronic active hepatitis. Gastroenterology 103:1290-1295. https://doi.org/10.1016/0016-5085(92)91518-9

51. Manns MP, Johnson EF, Griffin KJ et al (1989) Major antigen of liver kidney microsomal autoantibodies in idiopathic autoimmune hepatitis is cytochrome P450db1. J Clin Invest 83:10661072. https://doi.org/10.1172/JCI113949

52. Zanger UM, Hauri HP, Loeper J et al (1988) Antibodies against human cytochrome P-450db1 in autoimmune hepatitis type II. Proc Natl Acad Sci USA 85:8256-8260

53. Gueguen M, Meunier-Rotival M, Bernard O, Alvarez F (1988) Anti-liver kidney microsome antibody recognizes a cytochrome P450 from the IID subfamily. J Exp Med 168:801-806

54. Kerkar N, Ma Y, Davies ET et al (2002) Detection of liver kidney microsomal type 1 antibody using molecularly based immunoassays. J Clin Pathol 55:906-909

55. Kerkar N, Choudhuri K, Ma Y et al (2003) Cytochrome P4502D6(193-212): a new immunodominant epitope and target of virus/self cross-reactivity in liver kidney microsomal autoantibody type 1-positive liver disease. J Immunol 170:1481-1489

56. Manns MP, Griffin KJ, Sullivan KF, Johnson EF (1991) LKM-1 autoantibodies recognize a short linear sequence in P450IID6, a cytochrome P-450 monooxygenase. J Clin Invest 88:1370-1378. https://doi.org/10.1172/JCI115443

57. Yamamoto AM, Cresteil D, Homberg JC, Alvarez F (1993) Characterization of anti-liver-kidney microsome antibody (antiLKM1) from hepatitis C virus-positive and -negative sera. Gastroenterology 104:1762-1767

58. Vergani D, Mieli-Vergani G (2002) Autoimmunity after liver transplantation. Hepatology 36:271-276. https://doi.org/10.1053/ jhep.2002.35339

59. Gilman AJ, Le AK, Zhao C et al (2018) Autoantibodies in chronic hepatitis $\mathrm{C}$ virus infection: impact on clinical outcomes and extrahepatic manifestations. BMJ Open Gastroenterol 5:e000203. https://doi.org/10.1136/bmjgast-2018-000203

60. Muratori L, Lenzi M, Ma Y et al (1995) Heterogeneity of liver/ kidney microsomal antibody type 1 in autoimmune hepatitis and hepatitis C virus related liver disease. Gut 37:406-412

61. Ma Y, Peakman M, Lobo-Yeo A et al (1994) Differences in immune recognition of cytochrome P4502D6 by liver kidney microsomal (LKM) antibody in autoimmune hepatitis and chronic hepatitis C virus infection. Clin Exp Immunol 97:94-99. https://doi.org/10.1111/j.1365-2249.1994.tb06585.x

62. Bogdanos D-P, Lenzi M, Okamoto M et al (2004) Multiple viral/ self immunological cross-reactivity in liver kidney microsomal antibody positive hepatitis $\mathrm{C}$ virus infected patients is associated with the possession of HLA B51. Int J Immunopathol Pharmacol 17:83-92. https://doi.org/10.1177/039463200401700112

63. Bogdanos DP, Ma Y, Hadzic N et al (2004) P0295 virus-self crossreactivity inducing de novo autoimmune hepatitis eightyears after liver transplantation. J Pediatr Gastroenterol Nutr 39:S169

64. Kerkar N, Hadzić N, Davies ET et al (1998) De-novo autoimmune hepatitis after liver transplantation. Lancet 351:409-413. https://doi.org/10.1016/S0140-6736(97)06478-7

65. Zimmerman HJ, Lewis JH, Ishak KG, Maddrey WC (1984) Ticrynafen-associated hepatic injury: analysis of 340 cases. Hepatology 4:315-323

66. Homberg JC, Andre C, Abuaf N (1984) A new anti-liver-kidney microsome antibody (anti-LKM2) in tienilic acid-induced hepatitis. Clin Exp Immunol 55:561-570

67. Beaune P, Dansette PM, Mansuy D et al (1987) Human antiendoplasmic reticulum autoantibodies appearing in a druginduced hepatitis are directed against a human liver cytochrome
P-450 that hydroxylates the drug. Proc Natl Acad Sci USA 84:551-555

68. Lecoeur S, André C, Beaune PH (1996) Tienilic acid-induced autoimmune hepatitis: anti-liver and-kidney microsomal type 2 autoantibodies recognize a three-site conformational epitope on cytochrome P4502C9. Mol Pharmacol 50:326-333

69. Crivelli O, Lavarini C, Chiaberge E et al (1983) Microsomal autoantibodies in chronic infection with the HBsAg associated delta (delta) agent. Clin Exp Immunol 54:232-238

70. Strassburg CP, Obermayer-Straub P, Alex B et al (1996) Autoantibodies against glucuronosyltransferases differ between viral hepatitis and autoimmune hepatitis. Gastroenterology 111:1576-1586

71. Philipp T, Durazzo M, Trautwein C et al (1994) Recognition of uridine diphosphate glucuronosyl transferases by LKM-3 antibodies in chronic hepatitis D. Lancet 344:578-581

72. Ahonen P, Myllärniemi S, Sipilä I, Perheentupa J (1990) Clinical variation of autoimmune polyendocrinopathy-candidiasis-ectodermal dystrophy (APECED) in a series of 68 patients. N Engl J Med 322:1829-1836. https://doi.org/10.1056/NEJM199006283222601

73. Clemente MG, Meloni A, Obermayer-Straub P et al (1998) Two cytochromes $\mathrm{P} 450$ are major hepatocellular autoantigens in autoimmune polyglandular syndrome type 1 . Gastroenterology 114:324-328

74. Martini E, Abuaf N, Cavalli F et al (1988) Antibody to liver cytosol (anti-LC1) in patients with autoimmune chronic active hepatitis type 2. Hepatology 8:1662-1666

75. Lapierre P, Hajoui O, Homberg JC, Alvarez F (1999) Formiminotransferase cyclodeaminase is an organ-specific autoantigen recognized by sera of patients with autoimmune hepatitis. Gastroenterology 116:643-649

76. Muratori L, Sztul E, Muratori P et al (2001) Distinct epitopes on formiminotransferase cyclodeaminase induce autoimmune liver cytosol antibody type 1 . Hepatology 34:494-501. https://doi.org/ 10.1053/jhep.2001.27179

77. Lenzi M, Manotti P, Muratori L et al (1995) Liver cytosolic 1 antigen-antibody system in type 2 autoimmune hepatitis and hepatitis C virus infection. Gut 36:749-754

78. Rigopoulou EI, Mytilinaiou M, Romanidou O et al (2007) Autoimmune hepatitis-specific antibodies against soluble liver antigen and liver cytosol type 1 in patients with chronic viral hepatitis. J Autoimmune Dis 4:2. https://doi.org/10.1186/1740-2557-4-2

79. Han S, Tredger M, Gregorio GV et al (1995) Anti-liver cytosolic antigen type 1 (LC1) antibodies in childhood autoimmune liver disease. Hepatology 21:58-62

80. Berg Stechemesser (1981) - Google Scholar. https://scholar. google.ch/scholar?hl=it\&as_sdt=0,5\&q=berg+stechemesser+ 1981. Accessed 20 Aug 2017

81. Stechemesser E, Strienz J, Berg PA (1987) Serological definition of new subgroup of patients with autoimmune chronic active hepatitis. Lancet 1:683

82. Stechemesser E, Klein R, Berg PA (1993) Characterization and clinical relevance of liver-pancreas antibodies in autoimmune hepatitis. Hepatology 18:1-9

83. Manns M, Gerken G, Kyriatsoulis A et al (1987) Characterisation of a new subgroup of autoimmune chronic active hepatitis by autoantibodies against a soluble liver antigen. Lancet 1:292-294

84. Ma Y, Okamoto M, Thomas MG et al (2002) Antibodies to conformational epitopes of soluble liver antigen define a severe form of autoimmune liver disease. Hepatology 35:658-664. https:// doi.org/10.1053/jhep.2002.32092

85. Wies I, Brunner S, Henninger J et al (2000) Identification of target antigen for SLA/LP autoantibodies in autoimmune hepatitis. Lancet 355:1510-1515

86. Volkmann M, Martin L, Bäurle A et al (2001) Soluble liver antigen: isolation of a $35-\mathrm{kd}$ recombinant protein (SLA-p35) 
specifically recognizing sera from patients with autoimmune hepatitis. Hepatology 33:591-596. https://doi.org/10.1053/jhep. 2001.22218

87. Gelpi C, Sontheimer EJ, Rodriguez-Sanchez JL (1992) Autoantibodies against a serine tRNA-protein complex implicated in cotranslational selenocysteine insertion. Proc Natl Acad Sci USA 89:9739-9743

88. Costa M, Rodríguez-Sánchez JL, Czaja AJ, Gelpí C (2000) Isolation and characterization of cDNA encoding the antigenic protein of the human tRNP(Ser)Sec complex recognized by autoantibodies from patients withtype-1 autoimmune hepatitis. Clin Exp Immunol 121:364-374

89. Herkel J, Heidrich B, Nieraad N et al (2002) Fine specificity of autoantibodies to soluble liver antigen and liver/pancreas. Hepatology 35:403-408. https://doi.org/10.1053/jhep.2002.30699

90. Mix H, Weiler-Normann C, Thimme R et al (2008) Identification of CD4 T-cell epitopes in soluble liver antigen/liver pancreas autoantigen in autoimmune hepatitis. Gastroenterology 135:2107-2118. https://doi.org/10.1053/j.gastro.2008.07.029

91. Zachou K, Weiler-Normann C, Muratori L et al (2020) Permanent immunosuppression in SLA/LP-positive autoimmune hepatitis is required although overall response and survival are similar. Liver Int 40:368-376. https://doi.org/10.1111/liv.14280

92. van der Woude FJ, Rasmussen N, Lobatto S et al (1985) Autoantibodies against neutrophils and monocytes: tool for diagnosis and marker of disease activity in Wegener's granulomatosis. Lancet 1:425-429

93. Falk RJ, Jennette JC (1988) Anti-neutrophil cytoplasmic autoantibodies with specificity for myeloperoxidase in patients with systemic vasculitis and idiopathic necrotizing and crescentic glomerulonephritis. N Engl J Med 318:1651-1657. https://doi. org/10.1056/NEJM198806233182504

94. Marzano AV, Raimondo MG, Berti E et al (2017) Cutaneous manifestations of ANCA-associated small vessels vasculitis. Clin Rev Allergy Immunol. https://doi.org/10.1007/ s12016-017-8616-5

95. Terjung B, Herzog V, Worman HJ et al (1998) Atypical antineutrophil cytoplasmic antibodies with perinuclear fluorescence in chronic inflammatory bowel diseases and hepatobiliary disorders colocalize with nuclear lamina proteins. Hepatology 28:332-340. https://doi.org/10.1002/hep.510280207

96. Hov JR, Boberg KM, Karlsen TH (2008) Autoantibodies in primary sclerosing cholangitis. World J Gastroenterol 14:37813791. https://doi.org/10.3748/wjg.14.3781

97. Roozendaal C, de Jong MA, van den Berg AP et al (2000) Clinical significance of anti-neutrophil cytoplasmic antibodies (ANCA) in autoimmune liver diseases. J Hepatol 32:734-741
98. Lindgren S, Nilsson S, Nässberger L et al (2000) Anti-neutrophil cytoplasmic antibodies in patients with chronic liver diseases: prevalence, antigen specificity and predictive value for diagnosis of autoimmune liver disease. Swedish Internal Medicine Liver Club (SILK). J Gastroenterol Hepatol 15:437-442. https://doi. org/10.1046/j.1440-1746.2000.02078.x

99. Terjung B, Söhne J, Lechtenberg B et al (2010) p-ANCAs in autoimmune liver disorders recognise human beta-tubulin isotype 5 and cross-react with microbial protein FtsZ. Gut 59:808816. https://doi.org/10.1136/gut.2008.157818

100. Targan SR, Landers C, Vidrich A, Czaja AJ (1995) High-titer antineutrophil cytoplasmic antibodies in type-1 autoimmune hepatitis. Gastroenterology 108:1159-1166

101. Zachou K, Rigopoulou E, Dalekos GN (2004) Autoantibodies and autoantigens in autoimmune hepatitis: important tools in clinical practice and to study pathogenesis of the disease. $\mathrm{J}$ Autoimmune Dis 1:2. https://doi.org/10.1186/1740-2557-1-2

102. Hov JR, Boberg KM, Taraldsrud E et al (2017) Antineutrophil antibodies define clinical and genetic subgroups in primary sclerosing cholangitis. Liver Int 37:458-465. https://doi.org/10.1111/ liv. 13238

103. Yoshida A, Matsuoka K, Ueno F et al (2021) Serum PR3-ANCA is a predictor of primary nonresponse to anti-TNF- $\alpha$ agents in patients with ulcerative colitis. Inflamm Intest Dis 6:117-122. https://doi.org/10.1159/000515361

104. Leung PSC, Rossaro L, Davis PA et al (2007) Antimitochondrial antibodies in acute liver failure: implications for primary biliary cirrhosis. Hepatology 46:1436-1442. https://doi.org/10.1002/ hep. 21828

105. Couto CA, Bittencourt PL, Porta G et al (2014) Antismooth muscle and antiactin antibodies are indirect markers of histological and biochemical activity of autoimmune hepatitis. Hepatology 59:592-600. https://doi.org/10.1002/hep.26666

106. Kroshinsky D, Stone JH, Bloch DB, Sepehr A (2009) Case records of the Massachusetts General Hospital. Case 5-2009. A 47-year-old woman with a rash and numbness and pain in the legs. N Engl J Med 360:711-720. https://doi.org/10.1056/ NEJMcpc0807822

107. Pisetsky DS (2017) Antinuclear antibody testing — misunderstood or misbegotten? Nat Rev Rheumatol 13:495-502. https://doi.org/ 10.1038/nrrheum.2017.74

Publisher's Note Springer Nature remains neutral with regard to jurisdictional claims in published maps and institutional affiliations. 